\title{
POSTER: Dagda - A Virtual Reality Experience for Pediatric Patients with Cancer in Chemotherapy
}

\author{
Carlos Eduardo Sarmento \\ Programa Talento Metrópole \\ Universidade Federal do Rio Grande do Norte \\ Natal, Brasil \\ cealvesarmento@gmail.com
}

\author{
Deborah Dantas \\ Programa Talento Metrópole \\ Universidade Federal do Rio Grande do Norte \\ Natal, Brasil \\ deboraharruda@hotmail.com \\ Hallysson Santos \\ Instituto Metrópole Digital \\ Universidade Federal do Rio Grande do Norte \\ Natal, Brasil \\ hallysson.diniz99@gmail.com \\ Matheus Andrade \\ Programa Talento Metrópole \\ Universidade Federal do Rio Grande do Norte \\ Natal, Brasil \\ matheus.mas132@hotmail.com
}

\author{
Daniel Guerra \\ Programa Talento Metrópole \\ Universidade Federal do Rio Grande do Norte \\ Natal, Brasil \\ daniel.guerra13@hotmail.com \\ Emanuel Arnaud \\ Programa Talento Metrópole \\ Universidade Federal do Rio Grande do Norte \\ Natal, Brasil \\ emanuel.arnaud@gmail.com \\ João Pedro Dias \\ Programa Talento Metrópole \\ Universidade Federal do Rio Grande do Norte \\ Natal, Brasil \\ joaopedro10782@gmail.com
}

\author{
Alyson Souza \\ Instituto Metrópole Digital \\ Universidade Federal do Rio Grande do Norte \\ Natal, Brasil \\ alyson@imd.ufrn.br
}

\begin{abstract}
-during the process of chemotherapy of pediatric patients with cancer, the discomfort proves to be one of the many challenges for the patient, intensified by the ease at which the child becomes upset or annoyed. As a form of distraction during part of the treatment, this poster proposes an application of virtual reality to mask the process, and additionally, allows for association within the cancer patient's situation.
\end{abstract}

Keywords - virtual reality, oncology, chemotherapy, pediatric

\section{INTRODUCTION}

Pediatric cancer is a series of diseases that are distinguished by the quick and uncontrollable proliferation of cells in the organism [3], affecting children and teenagers. The most used type of treatment is chemotherapy, since most of the diseases in the genus are sensitive to it. A lumbar puncture is used to administer the needed medicine.

Often in literature, strategies on how to counteract medical procedures have been discussed, given that cancer treatment is intense and hard to withstand [6]. Several forms have been evaluated with the purpose of ease such difficulties and promote well-being to these children.

Virtual reality (VR) has been used during the last years in many areas, such as entertainment, education and health [1],
[4]. It has been proved as effective as a distracting activity in reducing the perception of pain and/or anxiety [5], [7], [8].

Therefore, the objective of this poster is to describe the development of a Virtual Reality for pediatric cancer patients that go through a lumbar puncture during chemotherapy. This strategy allows the child to be the protagonist during the treatment while the virtual reality immersion, bringing support and empowerment.

\section{MATERIALS AND METHODS}

Knowing the difficulties presented, the proposed experience is an interactive video in Virtual Reality in which the child cannot control the video but can interact with the environment. Due to possible alterations during the puncture procedure, the responsible nurse can control the rhythm of the experience through a secondary device, connected to the child's device.

For the project, the development engine Unity, the RV module Google VR and assets from Blender 2.8, either our own or from third parties. The connection between the nurse and the child is through a local network made from Forge. An Android smartphone and virtual reality glasses are used for the experience. 


\section{A. Video module}

The video was elaborated for the Android platform and will be applied along with VR glasses and headphones. It was opted to produce a passive session with the intention to not interfere with the medical procedure, preventing the child's movement and use of their arms.

The experience has been divided into two parts; the first, with narration and contextualization of the story. This introductory part is when the nurse will prepare the material to perform the puncture and the child is introduced to the story. The second part consists of an interaction between the characters, during which the puncture will occur.

\section{B. Script}

The script was elaborated as a group following the technique of storytelling. The plot had the objective of being short, concise and captativing. The intention of it being realized in a short amount of time is related to the fact that nausea can occur as a side effect of a virtual reality experience, already being reported in other works.

The protagonist helps a planet called Dagda to recover from an environmental crisis. In order to accomplish this, they travel to the planet $\mathrm{T}-8$, where there is a mineral called MTX (inspired by the name of one of the main medications used during the treatment), able to save Dagda. During the experience, the child goes through situations that resemble the puncture in order to obtain the mineral and fulfill their mission.

\section{Modeling and Animation}

With the help of Blender, the team developed the models necessary, based on previously made drafts, and adapting them to Lowpoly [2], seeing that the experience will be on a smartphone, and therefore, the environment must be optimized so the rendering will be fast and light enough. Furthermore, rigging and animation of the models were done.

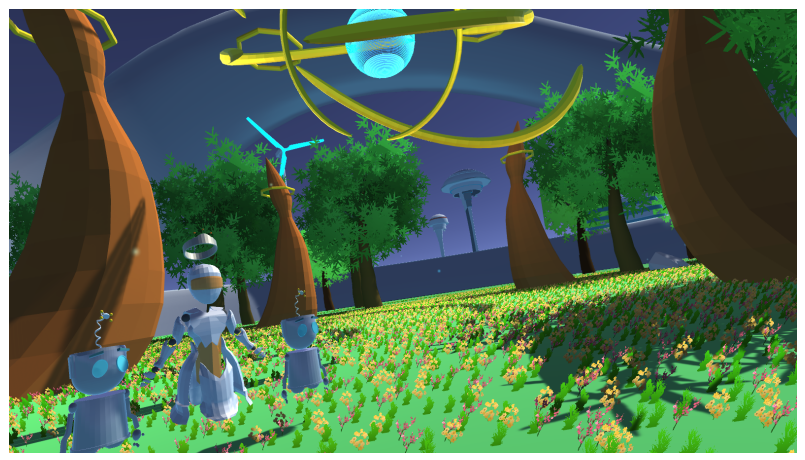

Fig. 1. Figure 1: one of the scenes of the experience.

\section{CONCLUSIONS}

This study is ongoing and is set to become a virtual reality experience for pediatric cancer patients that go through puncture during chemotherapy. The proposal is to facilitate the process of coping and support the treatment using VR technology.

In future works, a pilot study of the experience is intended to be applied to children at a pediatric hospital in the city of Natal, focusing on the treatment of pediatric patients with cancer. The objective is to verify if the use of VR brings any benefits during invasive procedures, as well as the enhancement of the experience.

The improvement through new mechanisms and interactive modes is an intention, that might proportion immersion and interactivity to the child in treatment. It is believed that the present study might contribute to the objective of ensuring a safe life and promoting well-being to patients with cancer, foreseen in the ONU's 2030 agenda.

Additionally, this project is within the interdisciplinary field of Psychology and Informational Technology, as well as the knowledge and sensibilization of the experience, based on interviews with health professionals. This aspect allows for the expansion of diagnostics and intervention among these fields.

\section{REFERENCES}

[1] BACCA, JORGE, ET AL, Augmented reality trends in education: a systematic review of research and applications. 2014.

[2] Autodesk (2006). Autodesk 3ds Max 9 essentials. Focal Press. p. 190 Retrieved 18 July 2011.

[3] Instituto Nacional de Câncer José de Alencar Gomes da Silva, Estimativa 2014: Incidência de Câncer no Brasil. Rio de Janeiro: Ministério da Saúde/ Instituto Nacional do Câncer. Rio de Janeiro: INCA, 2014.

[4] F. PALLAVICINI, L. MORGANTI, B. DIANA, O. REALDON, V. ZURLONI, F. MANTOVANI, Mobile Virtual Reality to Enhance Subjective Well-Being. In Encyclopedia of Information Science and Technology, Fourth Edition. IGI Global, 2018, pp. 6223-6233.

[5] W. H. LI, J. O. CHUNG, E. K. HO, The effectiveness of therapeutic play, using virtual reality computer games, in promoting the psychological well-being of children hospitalised with cancer. Journal of Clinical Nursing, 20(15-16), 2011, pp. 2135-2143.

[6] V. CARRIERI-KOHLMAN, G. KIECKHEFER, S. JANSONBJERKLIE, J. SOUZA, The sensation of pulmonary dyspnea in school-age children. Nursing Research, 1991.

[7] J. GERSHON, E. ZIMAND, R. LEMOS, B. O. ROTHBAUM L. HODGES, Use of virtual reality as a distractor for painful procedures in a patient with pediatric cancer: a case study. CyberPsychology Behavior, 6(6), 2003, pp. 657-661.

[8] S. M. SCHNEIDER, M. L. WORKMAN, Virtual reality as a distraction intervention for older children receiving chemotherapy. Pediatric Nursing, 26(6), 2000. 